\title{
A Case of Giant Posterior Mediastinal Mass: Gastrointestinal Stromal Tumor Developed in Neurofibromatosis Type 1 Patient.
}

\section{Volkan ASLAN ( $\sim$ dr.volcanaslan@gmail.com )}

Gazi University Faculty of Medicine: Gazi Universitesi Tip Fakultesi https://orcid.org/0000-0001-56853748

\section{Fatih Gürler}

Gazi University Faculty of Medicine: Gazi Universitesi Tip Fakultesi

ozan yazıcı

Gazi University Faculty of Medicine: Gazi Universitesi Tip Fakultesi

\section{özlem erdem}

Gazi University Faculty of Medicine: Gazi Universitesi Tip Fakultesi

\section{ali çelik}

Gazi University Faculty of Medicine: Gazi Universitesi Tip Fakultesi

\section{dilvin özkan}

Gazi University Faculty of Medicine: Gazi Universitesi Tip Fakultesi nuriye özdemir

Gazi University Faculty of Medicine: Gazi Universitesi Tip Fakultesi

\section{Research Article}

Keywords: Giant Posterior Mediastinal Mass, Neurofibromatosis Type 1, Gastrointestinal Stromal Tumor

Posted Date: August 3rd, 2021

DOI: https://doi.org/10.21203/rs.3.rs-748331/v1

License: (c) (1) This work is licensed under a Creative Commons Attribution 4.0 International License. Read Full License 


\section{Abstract}

Introduction: Gastrointestinal Stromal Tumors mostly located in the stomach and esophageal GIST is extremely rare. Various genetic disorders increase the risk of developing GIST, among these, NF-1 is the most common. A case of posterior mediastial GIST developing in the neurofibromatosis patient has not been reported yet.

Case: A 48-year-old male patient is being evaluated with complaints of dyspnea and progressive dysphagia. Computed tomography detected a cystic, lobulated contour mass that was located at the posterior mediastinum and measuring $11 \times 14 \times 12 \mathrm{~cm}$. The giant semisolid mass has been dissected from adjacent the vertebra, the esophagus, pericardium and inferior pulmonary vein and Histopathological examination revealed GiST. Pathological examination of skin lesions confirmed NF-1. Finally, NF-1associated posterior mediastinal GIST was diagnosed and adjuvant imatinib treatment was initiated.

Conclusion: To the best our knowledge, this patient was the first case, who diagnosed with posterior mediastinal GIST developing on the basis of NF-1.

\section{Introduction:}

Gastrointestinal Stromal Tumors (GISTs) are the most common tumors of mesenchymal origin of the gastrointestinal tract and originate from Cajal cells (1). Mostly located in the stomach (55.6\%), other places are small intestine (31.8\%) colon (6\%). Esophageal GIST is extremely rare (0.7\%) (2). The clinical features of GISTs may show heterogeneity and tumor size and mitotic activity are the most prognostic features used in determining the risk of metastasis. In case of GIST located outside of the gastrointestinal tract, they are called extra-gastrointestinal stromal tumors (EGIST) and they account for less than $5 \%$ of all (3). EGISTs generally have the same immunohistochemical properties as GIST and in very rare cases, can occur in the retroperitoneum, mesentery and omentum (4).

Various genetic disorders increase the risk of developing GIST. Among these, NF-1 is the most common. The incidence of GIST in NF-1 is not clearly known. Analysis in a patient group of 3,000 GIST cases shows that NF-1 patients have at least a 45 -fold higher risk of developing GIST than the general population (5). Posterior mediastinal GIST is extremely rare in the literature, and about 13 case reports originating from the esophagus and stomach have been reported. A case of posterior mediastial GIST developing in the neurofibromatosis patient has not been reported yet.

Here, we present a case of esophageal GIST, which does not have complaints about skin lesions that have existed since childhood and was not investigated, but was diagnosed with progressive dyspnea and dysphagia that started in recent years and developed on the basis of neurofibromatosis.

\section{Case Report:}


A 48-year-old male patient is being evaluated with complaints of dyspnea, which has been present for about 2 years and progressively increased by limiting effort capacity. In addition to that he had progressive dysphagia that occurred 8 months ago.On physical examination of the patient, ECOG performance status was 1 and widespread nodules of the same color as the skin and milky brown macular lesions were observed on the whole trunk (Fig. 1). In his family history his father died at the age of 55 due to a cerebrovascular event and had similar skin lesions with our patient. One of his siblings had similar skin lesions, but he did not have any complaints.

Computed tomography examination was performed for the complaints of the patient and thorachal computed tomography (CT) detected a cystic, lobulated contour mass that was located at the posterior mediastinum and measuring $11 \times 14 \times 12 \mathrm{~cm}$ (Fig. 2). The mass caused compression on the esophagus and both lungs. In the upper gastrointestinal endoscopy examination a narrowing of the lumen of the esophagus due to external compression was observed.

Postero lateral thoracotomy was performed with the diagnosis of a posterior mediastinal mass. The giant semisolid mass located in the posterior mediastinum, has been dissected from adjacent the vertebra, the esophagus, pericardium and inferior pulmonary vein. In macroscopic evaluation the tumor was measured as $13.5 \times 10 \mathrm{~cm}$ and was encapsulated. Spindle-shaped tumor cells were observed in pathological examination (Fig. 3). The pathological material contained mild atypia and the mitotic counts were 3/50. Immunohistochemical analysis of tumor cells was compatible with GIST. (CD117 and CD34 were diffuse positive (Fig. 3 ), S-100, SMA, DESMIN, EMA, and DOG-1 negative; Ki67 index 1\%, SDH-A and SDH-B loss were not observed ).

Skin biopsy was performed in the patient who was thought to have neurofibromatosis. The pathology result was reported as neurofibroma. The diagnosis of NF-1 was confirmed by the genetic evaluation of the patient.

Adjuvant imatinib treatment was initiated for the patient, who was considered to be at high risk and the patient has been followed up in remission for 6 months with imatinib treatment.

\section{Discussion:}

In the guidelines for the diagnosis and management of NF1, clinical symptoms mostly occur during childhood or adolescence, however our patient was diagnosed at the age of 48 due to sociocultural problems. Although it was not proven in our case, there was a positive family history. These findings meet the clinical and diagnostic criteria for NF1. In addition, the diagnosis was clarified with the genetic test. The most important feature of our patient is that it is a giant posterior mediastinal GIST case developing on the basis of NF1.

GISTs associated with NF1 are multiple and usually low-grade, typically affecting the jejunum, ileum, duodenum, and stomach (6). In the examination of 252 cases with GIST on the basis of NF1, it was reported that the patients were younger and the tumors were significantly smaller. In the same study, 
tumor localization is mainly located in the jejunum and ileum in the NF1 subgroup while it is in the stomach in the sporadic group. In addition, tumors in the NF1 subgroup were observed to have low risk criteria compared to sporadic GISTs (7). In addition, posterior mediastinal GIST case was extremely rare in the literature. In a recent literature review, a study where 12 GIST cases were reported after the diagnosis of posterior mediastinal mass indicated that most originated from the esophagus and 2 cases originated from the stomach. It has been reported to occur mostly in the elderly and present as giant masses (8). In our case, it is noteworthy that the mediastinal mass can reach giant dimensions at a younger age. To the best our knowledge, in the literature the current patient was the first case diagnosed with posterior mediastinal GIST developing on the basis of NF-1.

Due to the rarity of esophageal GISTs, the optimal surgical method is unclear. While enucleation is generally recommended for smaller tumors $(2-5 \mathrm{~cm}$ in size), esophagectomy is recommended for GISTs larger than $9 \mathrm{~cm}$ (9). In our case, there was no esophageal invasion and a bulky mass was totally removed without the need for esophageal surgery. The optimal surgical method is not known, and there is not enough data on the risk of recurrence. In a study of 135 esophageal GIST cases, Feng et al. reported that 5-year DFS was $65.1 \%$ and disease-specific survival (DSS) was $65.9 \%$.Tumor size was an independent risk factor for the prognosis of esophageal GISTs (10). Nakano et al. evaluated the data of 139 operated patients of 153 esophageal GIST patients reported in the literature and they found that 23 (16.5\%) patients had recurrence, 5 (3.6\%) of them have local recurrence and $18(12.9 \%)$ of them have distant metastases. The average time to relapse was 40 months, 5-year disease-free survival (DFS) and

overall survival (OS) were reported as $57 \%$ and $89 \%$, respectively. They recommended long-term follow-up because, recurrence occurs even after years (11).

In patients with high-risk GIST three-year treatment with imatinib was recommended adjuvant treatment (12). R0 resection was performed in all 12 cases with a diagnosis of posterior mediastinal GIST. In 9 cases with follow-up data, the median follow-up period was 24 months and 8 patients were followed up without adjuvant therapy and without any disease (8). In one case, Constantinou $\mathrm{S}$ et al. started adjuvant imatinib treatment in a patient whose recurrence risk was evaluated as high (13). We considered our patient to be at high risk for recurrence due to the size of the tumor and initiated adjuvant imatinib treatment.

\section{Conclusion:}

Here, an adult case of GIST developing on the basis of neurofibromatosis type 1 diagnosed with a posterior mediastinal mass, which is an extremely rare form, is presented. The treatment algorithm of these patients has not been clearly demonstrated, and treatment should be planned according to the limited case reports.

\section{Declarations:}

\section{- Author Contributions:}


All authors contributed to the study conception and design. Material preparation, data collection and analysis were performed by [Volkan Aslan], [Fatih Gürler], [Ozan Yazıcı], [Özlem Erdem], [Ali Çelik], [Dilvin Özkan], [Nuriye Özdemir], The first draft of the manuscript was written by [volkan Aslan], and all authors commented on previous versions of the manuscript. All authors read and approved the final manuscript.

- To be used for non-life science journals.

- Funding: This research did not receive any specific grant from funding agencies in the public, commercial, or not-for-profit sectors.

- Conflict of interest: The authors report no conflict of interest.

- Availability of data and material (data transparency): applicable

- Code availability (software application or custom code): not applicable

- To be used for life science journals + articles with biological applications

- Ethics approval (include appropriate approvals or waivers): not applicable

-Consent to participate (include appropriate statements): not applicable

- Consent for publication (include appropriate statements): not applicable

- Patient consent: As required by the routine operation of our clinic, the approval of the patient was obtained for academic purposes without specifying an identity.

\section{References:}

1. Kindblom L-G, Remotti HE, Aldenborg F, Meis-Kindblom JM. Gastrointestinal pacemaker cell tumor (GIPACT): gastrointestinal stromal tumors show phenotypic characteristics of the interstitial cells of Cajal. The American journal of pathology. 1998;152(5):1259.

2. Søreide K, Sandvik OM, Søreide JA, Giljaca V, Jureckova A, Bulusu VR. Global epidemiology of gastrointestinal stromal tumours (GIST): a systematic review of population-based cohort studies. Cancer epidemiology. 2016;40:39-46.

3. Sircar K, Hewlett B, Huizinga J, Chorneyko K, Berezin I, Riddell R. Interstitial cells of Cajal as precursors of gastrointestinal stromal tumors. The American journal of surgical pathology. 1999;23(4):377-89.

4. Goh BK, Chow PK, Kesavan SM, Yap W-M, Chung Y-FA, Wong W-K. A single-institution experience with eight CD117-positive primary extragastrointestinal stromal tumors: critical appraisal and a comparison with their gastrointestinal counterparts. Journal of Gastrointestinal Surgery. 2009;13(6):1094-8. 
5. Miettinen M, Fetsch JF, Sobin LH, Lasota J. Gastrointestinal stromal tumors in patients with neurofibromatosis 1: a clinicopathologic and molecular genetic study of 45 cases. The American journal of surgical pathology. 2006;30(1):90-6.

6. Andersson J, Sihto H, Meis-Kindblom JM, Joensuu H, Nupponen N, Kindblom L-G. NF1-associated gastrointestinal stromal tumors have unique clinical, phenotypic, and genotypic characteristics. The American journal of surgical pathology. 2005;29(9):1170-6.

7. Salvi PF, Lorenzon L, Caterino S, Antolino L, Antonelli MS, Balducci G. Gastrointestinal stromal tumors associated with neurofibromatosis 1: a single centre experience and systematic review of the literature including 252 cases. International journal of surgical oncology. 2013;2013.

8. Yin X, Shen C, Yin Y, Cai Z, Chen Z, Zhang B. Giant gastric stromal tumor mimicking as a posterior mediastinal mass: a case report and literature review. Medicine. 2018;97(41).

9. Jiang P, Jiao Z, Han B, Zhang X, Sun X, Su J, et al. Clinical characteristics and surgical treatment of oesophageal gastrointestinal stromal tumours. European journal of cardio-thoracic surgery. 2010;38(2):223-7.

10. Feng F, Tian Y, Liu Z, Xu G, Liu S, Guo M, et al. Clinicopathologic features and clinical outcomes of esophageal gastrointestinal stromal tumor: evaluation of a pooled case series. Medicine. 2016;95(2).

11. Nakano A, Akutsu Y, Shuto K, Uesato M, Kono T, Hoshino I, et al. Giant esophageal gastrointestinal stromal tumor: report of a case. Surgery today. 2015;45(2):247-52.

12. DeMatteo RP, Ballman KV, Antonescu CR, Maki RG, Pisters PW, Demetri GD, et al. Placebo-controlled randomized trial of adjuvant imatinib mesylate following the resection of localized, primary gastrointestinal stromal tumor (GIST). Lancet. 2009;373(9669):1097.

13. Constantinoiu S, Gheorghe M, Popa L, Ciocea C, losif C, Tiutiuca R, et al. Giant Esophageal GIST: Diagnostic and Therapeutic Challenge - Case Report. Chirurgia (Bucur). 2015;110(3):300-7.

\section{Figures}




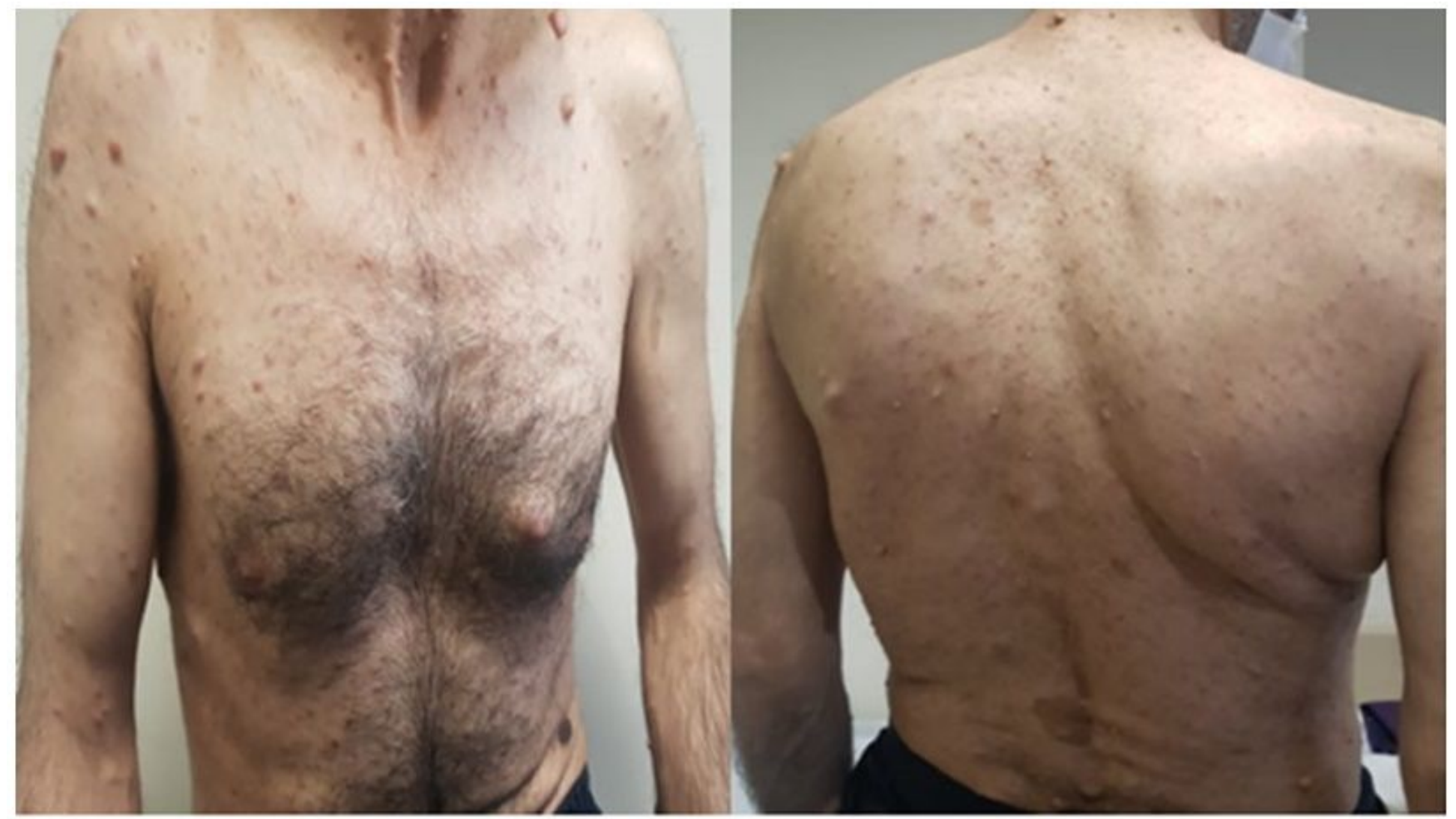

\section{Figure 1 .Neurofibromas and cafe au lait spots.}

Figure 1

See image above for figure legend. 


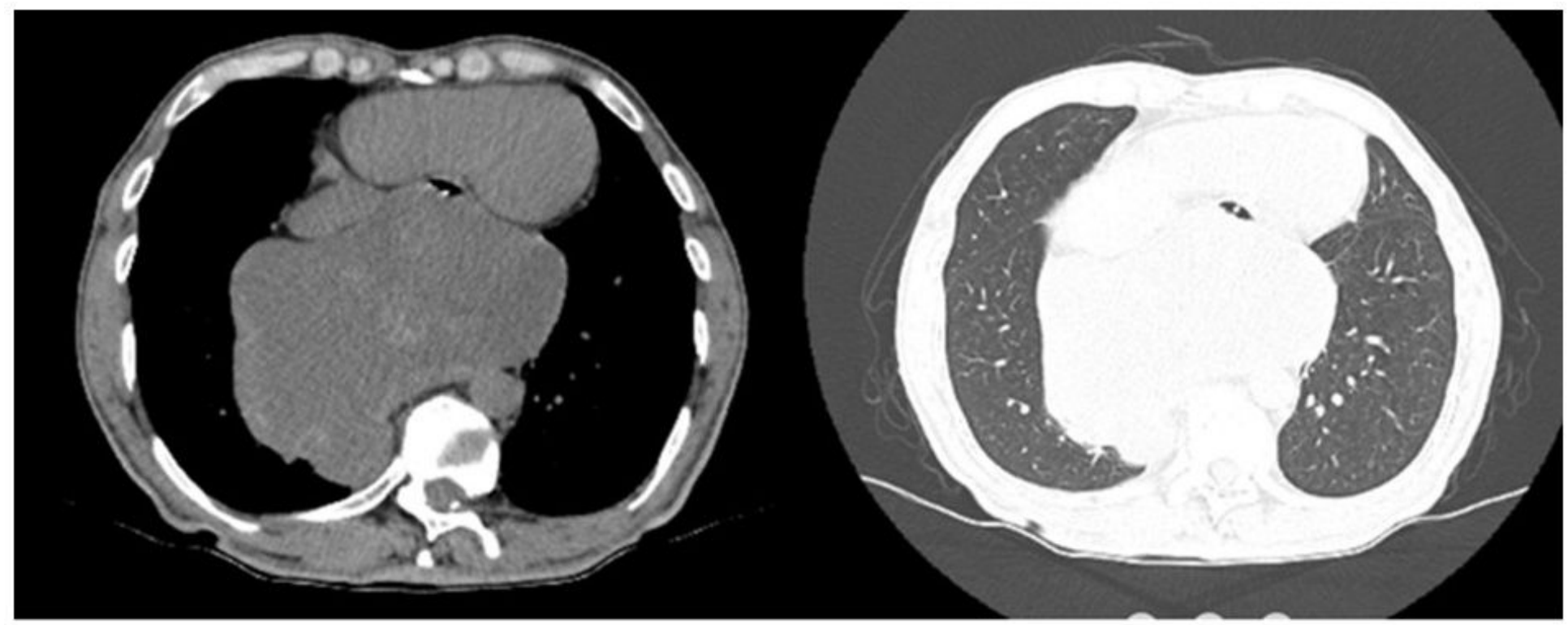

Figure 2. Giant mediastinal mass, $11 \times 14 \times 12 \mathrm{~cm}$ in size, located in posterior mediastinum. The esophagus and lower part of the heart were pushed anteriorly due to the mass compression.

Figure 2

See image above for figure legend. 


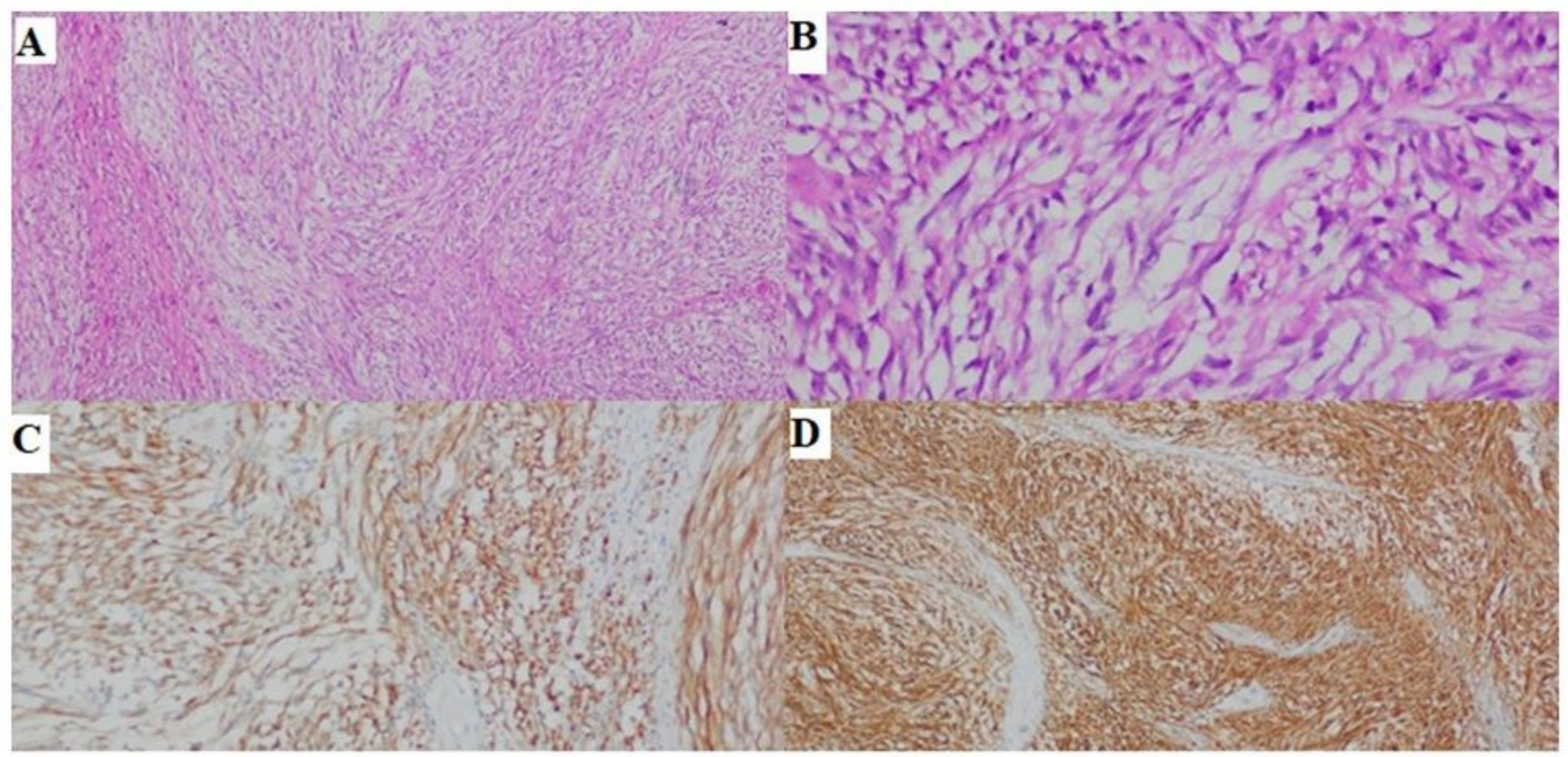

\section{Figure III}

A. Spindle cell type gastrointestinalstromal tumours (GIST) consist of fascicles of uniform spindle cells with eosinophilic cytoplasm

B. Spindle cell type gastrointestinalstromal tumours (GIST) consist of fascicles of uniform spindle cells with eosinophilic cytoplasm

C. Immunohistochemical staining positive for c-kit (CD117).

D. Immunohistochemical staining positive for c-kit (CD34).

Figure 3

See image above for figure legend. 